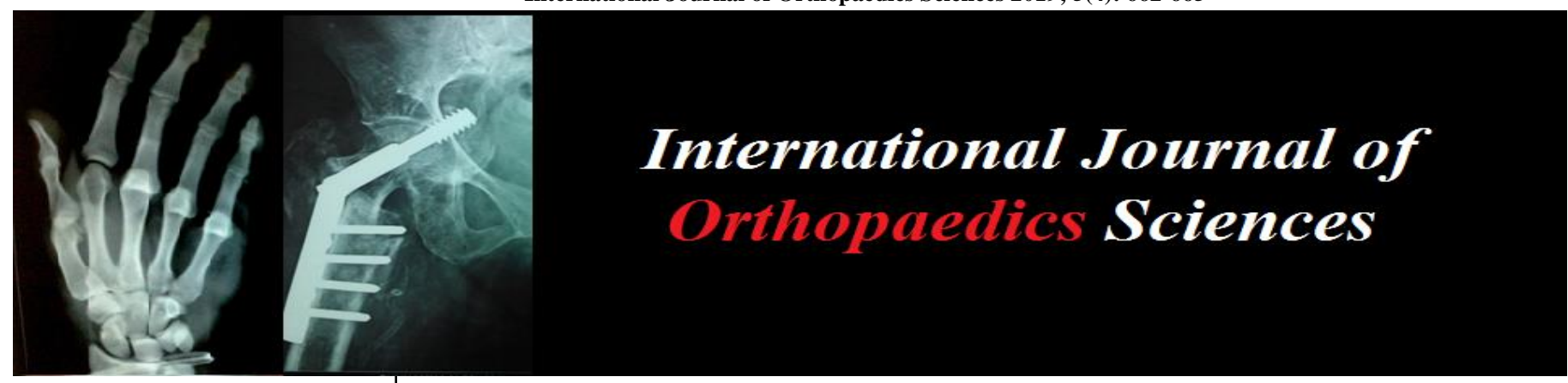

E-ISSN: 2395-1958

P-ISSN: 2706-6630

IJOS 2019; 5(4): 662-665

(C) 2019 IJOS

www.orthopaper.com

Received: 06-08-2019

Accepted: 10-09-2019

Dr. Mohammad Asimuddin Associate Professor, Department of Orthopaedics, Kbnims, Kalaburagi, Karnataka, India

Dr. Mohd. Mujtaba Hussain

Residents, Department of

Orthopaedic Kbnims

Kalaburagi, Karnataka, India

Dr. Ambreen

Residents, Department of

Orthopaedic Kbnims

Kalaburagi, Karnataka, India

Corresponding Author:

Dr. Mohammad Asimuddin

Associate Professor, Department

of Orthopaedics, Kbnims,

Kalaburagi, Karnataka, India

\section{A clinical study of proximal femoral nail in the management of intertrochanteric femoral fractures}

\author{
Dr. Mohammad Asimuddin, Dr. Mohd. Mujtaba Hussain and Dr. Ambreen
}

DOI: https://doi.org/10.22271/ortho.2019.v5.i41.1750

\section{Abstract}

Background: Trochanteric fracture of the femur is a common orthopaedic injury in the geriatric population. The objective of the study was to assess the clinical effectiveness of proximal femoral nail in the management of intertrochanteric fractures by looking at the rate of union, complications and functional outcome.

Methods: Thirty cases of intertrochanteric fractures of femur were included in the study. All these cases were fixed with proximal femoral nail. The mean age of the patient was 59.4 years. The male to female ratio was 2:1, and left side was involved in 13 cases and 17 had right sided injuries. The mechanism of injury was due to slip and fall in $25(83.33 \%)$ patients and RTA in $5(16.66 \%)$ patients. In our study 22 patients had systemic co-morbidity. The average operating time was 74 mins. (40 min -100 min)

Results: The average duration of hospital stay was 14.3 days. All patients were followed up regularly at 6 weeks, 3 months, and 6 months till fracture union. Functional and anatomical results were assessed using modified Harris hip score. In our study of 30 patients 13 cases $(43.33 \%)$ had excellent results, 11 cases $(36.66 \%)$ had good results, 5 cases $(16.66 \%)$ had fair results and 1 case $(3.33 \%)$ had poor results Conclusion: Proximal femoral nail is an excellent technique for the management of intertrochanteric fractures of femur as it creates a biomechanical stable construct allowing early weight bearing.

Keywords: intertrochanteric femur fracture, proximal femoral nail

\section{Introduction}

Intertrochanteric fractures are relatively common injuries in adults and elderly individuals. In young individuals intertrochanteric fractures are result of high energy trauma while minimal trauma is required for elderly ${ }^{[1]}$.

The incidence of intertrochanteric fracture is rising because of increasing number of senior citizens with osteoporosis. By 2040 the incidence is estimated to be doubled. The figures may be much more in India. Problems of these fractures are (1) associated with substantial morbidity and mortality (2) malunion (3) implant failure, cutout of head and penetration into hip (4) great financial burden to the family (5) associated medical problem like diabetes, hypertension ${ }^{[2]}$.

The trochanteric femur fractures can be managed by conservative methods and there is usually union of the fracture. If suitable precautions are not taken, it undergoes malunion, leading to varus and external rotation deformity, shortening and restriction of hip movements. It is also associated with complications like prolonged immobilization leads to bedsores, deep vein thrombosis and respiratory infections. The standard care of trochanteric fractures is surgical fixation, closed reduction and internal fixation which increases patient comfort, facilitate nursing care and decrease hospital stay ${ }^{[3]}$.

Dynamic hip screw (DHS) has been the standard implant in treating trochanteric fractures. However, when compared with the intramedullary implants, it has a biomechanical disadvantage because of a wider distance between the weight bearing axis and the implants ${ }^{[4]}$. Surgical treatment has improved considerably in recent years with advent of newer fixation devices and better understanding of the mechanics of fracture healing of the osteoporotic bone [5]. The latest implant is proximal femoral nail, which is a collapsible device with added rotational stability for trochanteric fracture management. This implant is a centromedullary 
device and biomechanically more sound. It has added advantages like minimal blood loss and small incision. The advantages of proximal femoral nail are to improve the rotational stability of proximal fracture fragments, combining the features of unreamed intramedullary femoral nail with a sliding, load bearing device, reduced incidence of implant cut out. Furthermore the tip of the nail was redesigned to reduce the bone stress so that it decreases the risk of intra and postoperative fractures of the femoral shaft ${ }^{[6]}$.

In view of these considerations, present study was conducted to assess clinical outcome and functional results of surgical management of intertrochanteric fractures with Proximal Femoral Nail.

\section{Methods}

This study was conducted in the department of Orthopaedics at Khaja Banda Nawaz Teaching and General Hospital, Kalaburagi, for a period of 2 years from Jan 2017 to Dec 2018. The study received clearance from ethical committee of the institution.

The inclusion criteria were patients with age more than 20 years, patients who are fit for surgery, fresh intertrochanteric fractures.

The exclusion criteria were patients unfit for surgery, patients with pathological fractures, patients with malunion and non union fractures, compound fractures and in children.

Patients were admitted and detailed history with co-morbid conditions, examination and investigation were done. X-ray pelvis with both hips joints and lateral view (if possible) were taken.

\section{Operative procedure}

Patient were given spinal or epidural anesthesia and shifted to a radiolucent fracture table in a supine position. Operative leg was put on traction.

Reduction was achieved by traction and internal rotation primarily and adduction of 10-15 degrees as required. Reduction was checked in a C-arm with anterior-posterior and lateral view. The tip of the greater trochanter was located by palpation and $5 \mathrm{cms}$ longitudinal incision taken proximal from the tip of the greater trochanter. A parallel incision was made in the fascia lata and gluteus medius was split in line with the fibres.

In AP view on $\mathrm{C}$-arm, the entry point is on the tip or slightly lateral to the tip of the greater trochanter. In lateral view guide wire position is confirmed in the center of the medullary cavity. The guide wire is inserted in this direction to a depth of $30 \mathrm{cms}$ with a $\mathrm{T}$ handle. After confirming satisfactory fracture reduction an appropriate size nail as determined pre operatively was assembled to the insertion handle and inserted manually as far as possible into the femoral opening. This step was done carefully without hammering by slight twisting movements of the hand until the hole for $8 \mathrm{~mm}$ screw is at the level of inferior margin of neck. In cases where satisfactory reduction was not possible by closed means, open reduction was done. The hip pin is inserted first to prevent the possible rotation of the medial fragment when inserting the neck screw. The length of the hip pin is indicated on measuring device and is calculated $5 \mathrm{~mm}$ before the tip of the guide wire. Drilling is done over the guide wire with $6.5 \mathrm{~mm}$ drill bit to a depth upto the length of hip pin previously measured. The same length $65 \mathrm{~mm}$ hip pin is inserted with the help of hexagonal cannulated screwdriver. Length and position to be confirmed with C-Arm and Guide wire is then removed. For neck screw, a measuring device is inserted over the $2.8 \mathrm{~mm}$ guide wire until it touches the bone. The correct length is indicated on the measuring device and calculated to end approximately $5 \mathrm{~mm}$ before the tip of the guide wire. This length is set on the $8 \mathrm{~mm}$ reamer by securing the fixation sleeve in correct position. Drilling is done over $2.8 \mathrm{~mm}$ guide wire till the fixation sleeve prevents further drilling. Neck screw is inserted using cannulated screw driver. Final position confirmed with image intensifier. Distally two screws are passed. Wound is closed in layers. Quadriceps exercises were taught and knee mobilization was done.

Patients were made to walk with the help of walking aid before discharge. Sutures were removed on $14^{\text {th }}$ post operative day.

\section{Follow up}

All patients were followed up at an interval of 6 week, 3 months and 6 months and further till union occurs. At every visit patients were assessed clinically regarding hip and knee function, walking ability, fracture union, deformity and shortening. Modified Harris Hip scoring system was used for evaluation.

\section{Harris hip scoring system (Modified)}

Maximum points possible -100

Pain relief- 44

Function- 47

Absence of deformity- 4

Range of motion- 5

\section{Total harris hip score \\ Score Rating}

90-100 Excellent

80-89 Good

70-79 Fair

$<70$ Poor

\section{Results}

This study involves 30 patients of intertrochanteric fractures treated by intramedullary fixation with PFN, both stable and unstable intertrochanteric fractures were included.

All cases were classified according to Boyd and Griffin classification of intertrochanteric fractures. 1 case $(3.33 \%)$ was type 1,13 cases $(43.33 \%)$ type 2,12 cases $(40 \%)$ was type 3 and 4 cases $(13.33 \%)$ type 4 . (Table -1 )

Table 1: Type of Fracture

\begin{tabular}{|c|c|c|}
\hline Type of fracture & No of patients & Percentage \\
\hline Type 1 & 1 & $3.33 \%$ \\
\hline Type 2 & 13 & $43.33 \%$ \\
\hline Type 3 & 12 & $40 \%$ \\
\hline Type 4 & 4 & 13.33 \\
\hline Total & 30 & $100 \%$ \\
\hline
\end{tabular}

In our study total of 22 patients had co-morbid conditions. 9 had hypertension, 7 had diabetes mellitus, 3 had both HTN and DM, 2 had COPD and 1 had both HTN and COPD.

The average blood loss was $85 \mathrm{ml}(50-150 \mathrm{ml})$, none required blood transfusion post operatively.

The average operative time after anesthesia was 74 minutes (40 min -100 min).

\section{Intra-operative complications}

In our study we had one case of varus angulation and in 2 patients we were unable to put derotation screw. in one case we had guide wire breakage and drill bit breakage. 


\section{Post-operative complications}

We had two cases of superficial wound infection which was managed with antibiotics. We had shortening of $2 \mathrm{cms}$ in 2 patients, one had varus angulation and one case had $\mathrm{z}$ effect. The average hospital stay was 14.3 days.

\section{Follow up}

All patients were followed up regularly at 6 weeks, 3 months and 6 months. (Fig 1)

Functional and anatomical results were assessed using Modified Harris Hip Score. (Table -2)

a. Pre op x-ray

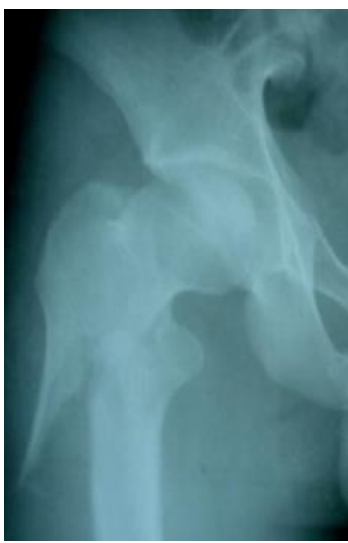

c. post op $6 \mathrm{wks}$

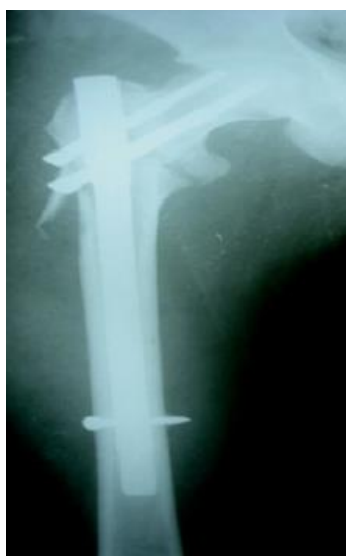

Fig 1: $x$-ray images fixed with PFN

Table 2: Function Results Using Modified Harris Hip Score

\begin{tabular}{|c|c|c|}
\hline Functional result & No. Of patients & Percentage \\
\hline Excellent & 13 & $43.33 \%$ \\
\hline Good & 11 & $36.66 \%$ \\
\hline Fair & 5 & $16.66 \%$ \\
\hline Poor & 1 & $3.33 \%$ \\
\hline Total & 30 & $100 \%$ \\
\hline
\end{tabular}

\section{Discussion}

The primary goal of the treatment has to be early mobilization to avoid secondary complications, which can be achieved by closed reduction and internal fixation. Intertrochanteric femur fractures may be repaired with either a sliding hip screw or a trochanteric nail.

The hip screw has been considered the device of choice because fracture union predictably occurs. A problem with sliding hip screw is collapse of the femoral neck, leading to loss of hip offset and shortening of the leg. Although some such sliding is expected, too much shortening is detrimental to hip function. Therefore, a new intramedullary device - proximal femoral nail was designed in 1996 which gives an advantage of minimally invasive surgery ${ }^{[7]}$.

Dynamic hip screw is considered the gold standard for treatment due to its favorable results and low rate of complications when used in the management of stable fractures ${ }^{[8]}$.

Intramedullary hip screw devices ${ }^{[9]}$. e.g., proximal femoral nail offers several potential advantages over the sliding hip screw and plate like:

a. An intramedullary fixation device provides more efficient load transfer than does a sliding hip screw, because of its location.

b. A shorter lever arm of the intramedullary device can decrease tensile strain on the implant so decreasing the risk of implant failure.

c. Because an intramedullary fixation device incorporates a sliding hip screw, the advantage of controlled fracture impaction is maintained.

d. The intramedullary location limits the amount of sliding and therefore limb shortening and deformity that can occur.

e. Insertion of intramedullary hip screw requires shorter operative time and less soft tissue dissection than a sliding hip screw, so decreasing the overall morbidity.

Simmermacher et al. ${ }^{[7]}$. (1999), in a clinical multicentric study, reported technical failures of PFN after poor reduction, malrotation or wrong choice of screws in $5 \%$ of the cases. In our study, we had $1(3.3 \%)$ patient with varus malunion.

W. M. Gadegone \& Y. S. Salphale ${ }^{[10]}$, in 2007, reported a study on Proximal femoral nail - an analysis of 100 cases of proximal femoral fractures with an average follow up of 1 year. Postoperative radiographs showed a near-anatomical fracture reduction in $88 \%$ of patients. The fracture consolidated in 4.5 months. No perceptible shortening was noted. Of the patients, $7 \%$ had superficial infections which were controlled with antibiotics, $82 \%$ had a full range of hip motion.

In our Study we had $100 \%$ near normal anatomical fracture reduction. We had 2 cases of shortening more than $1 \mathrm{~cm}$, two cases $(6.66 \%)$ of superficial wound infection, we encountered no non-union.

Preetesh Endigeri et al. ${ }^{[11]}$ encountered complications and treatment failure in $11(22 \%)$ patients. Early complications include inadequate reduction in one patient $(2 \%)$, failure to put derotation screw in one patient $(2 \%)$, difficulty in distal locking in one patients $(2 \%)$, varus deformity in one patient $(2 \%)$, superficial infection in two patients (4\%), implant failure in two patients (4\%), and $\mathrm{z}$ effect in one patient (2\%). Other complications include shortening in one patient $(2 \%)$ and malunion in one patient (2\%).

In our study of 30 cases, functional results were evaluated with Modified Harris Hip Score. 13 cases (43.33\%) had excellent results, 11 cases $(36.66 \%)$ had good results, 5 cases $(16.66 \%)$ had fair results and 1 case $(3.33 \%)$ had poor result, with $2(6.66 \%)$ cases of superficial, 2 cases $(6.66 \%)$ of shortening, $1(3.33 \%)$ case of varus angulation and 1 case of $\mathrm{z}$ effect.

Excellent to good results were seen in $80 \%$ of the cases which is similar to Prajapati $\mathrm{P}$ et al. ${ }^{[12]}$.

Although cost of the implant is the major factor in proximal femoral nail as compared to other implants, but does not makes much of diffecnce as:

- Less operative time thus reducing the cost

- No or less need of transfusion of blood 
- Post-operative antibiotics were used less reducing the cost of the drugs

- Less hospital stay

- Early return to daily activities

- Early return to work

\section{Conclusion}

In conclusion, Proximal femoral nail is an excellent technique for the management of intertrochanteric fractures of femur, It creates a biomechanically stable construct allowing early weight bearing. It is a relatively easy procedure and reduces the morbidity and mortality in elderly patient.

\section{References}

1. Lavelle DG. Fractures of hip. In: canale ST, editor. Campbell's operative orthopaedics. $10^{\text {th }}$ ed. St. louis: Mosby, Inc. 2003; 3:2873-938.

2. Kulkarni GS, Rajiv Limaye, Milind Kulkarni, Sunil Kulkarni. Current Concept Review Intertrochanteric Fractures. Indian Journal of Orthopaedics. 2006; 40(1):16-23.

3. Chirodian N, Arch B, Parker MJ. Sliding hip screw fixation of Trochanteric hip fracture: outcome of 1024 procedures. Injury. 2005; 36:793-800.

4. Huang X, Leung F, Xiag Z, Tan PY, Yang T, Wei DQ, Yu X. Proximal femoral nail versus dynamic hip screw fixation for trochanteric fractures: met analysis of randomized controlled trials. Sci World J. 2013; 10:355361.

5. Barquet A, Francescoli L, Rienzi D, Lopez L. Intertrochanteric subtrochanteric fractures: treatment with the long Gamma nail. J Orthop Trauma. 2000; 14:324328.

6. Huber SM, Heining SM, Euler E. Pertrochanteric fracture fixation: photo elastic stress measurement comparing dynamic hip screw, y-nail and proximal femur nail. $\mathbf{J}$ Bone Joint Surg [Br]. 1997; 79-B(Suppl II):166.

7. Simmermacher RKJ, Bosch AM, Van der Werken C. The AO ASIF-proximal femoral nail (PFN): a new device for the treatment of unstable proximal femoral fractures. Injury. 1999; 30:327-32.

8. Klinger HM, Baums MH, Eckert M, Neugebauer R. A comparative study of unstable per- and intertrochanteric femoral fractures treated with dynamic hip screw (DHS) and trochanteric butt- press plate vs. proximal femoral nail (PFN). Zentralbl Chir. 2005; 130:301-6.

9. Bucholz RW, Heckman JD, Koval KJ, Zukerman JD. Rockwood and Green's Fractures in Adults. $6^{\text {th }}$ ed., Philadelphia: Lippincott Williams \& Wilkins, 2005.

10. Gadegone WM, Salphale YS. Department of orthopaedics and traumatology, chandrapur multispeciality hospital, chandrapur - 442401 - India. Proximal femoral nail - an analysis of 100 cases of proximal femoral fractures with an average follow up of 1 year Int Orthop. 2007; 31(3):403-408.

11. Preetesh Endigeri, Pattanashetty OB, Dayanand Banapatti $\mathrm{B}$, Arravind pillai, Ullas T. Outcome of intertrochanteric fractures treated with proximal femoral nail: A prospective study. J orthop Traumatol Rehabil. 2015; 8:25-9.

12. Prajapati $\mathrm{P}$ et al. Outcome of intertrochanteric fracture www.jrmds.in. Journal of Research in Medical and Dental Science | Vol. 4 | Issue 3 | July - September, 2016. 